\title{
2006-2052: PROFESSIONAL DEVELOPMENT AND AWARENESS BUILDING FOR TEACHERS IN THE AREA OF ADVANCED MATERIALS
}

\section{Ajit Kelkar, North Carolina A\&T State University}

Ajit Kelkar is a Professor of Mechanical Engineering at NC A\&T State University. He is the Associate Director of the Center for Advanced Materials and Smart Strucrures. His research areas include composite materials, finite element and numerical analysis, fatigue and fracture mechanics. He is a member of ASME, ASM, ASEE and AIAA.

\section{Ronnie Bolick, North Carolina A\&T State University}

Ronnie Bolick is Research Scientist at NC A\&T SU. He holds a PhD and MS degree in Mechanical Engineering from NC A\&T SU and a Batchelor's Degree in Applied Physics from Appalachian State University with a Minor in Math. He was Senior R\&D Test Engineer at Thomas Built Buses, Inc. for 11 years. His research areas are in instrumentation, fatigue and durability and finite element analysis. He is a member of ASEE, ASME, SAE, SME and ISA.

\section{Vijay Krishnan, North Carolina A\&T State University}

Vijay Krishnan is an Adjunct Assistant Professor in the department of Computational Science and Engineering. His research interests include composite materials, finite element modeling, numerical analysis, low velocity impact analysis and visualization. He is a member of ASTM

\section{William Craft, North Carolina A\&T State University}

William J. Craft is a NIA liaison professor. He is also a member of the Center for Advanced Materials and Smart Structures at North Carolina A\&T State University. His research interests include plates and shells, numerical analysis, computational mechanics and smart structures. He is a memeber of ASEE,AIAA and ASME. 


\title{
Professional Development and Awareness Building for Teachers in the Area of Advanced Materials
}

\begin{abstract}
On September 26, 2002, the National Institute of Aerospace, NIA, was created near NASA's Langley Research Center in Hampton, VA as a result of a winning proposal submitted from the AIAA and a 6-university team in response to a broad agency announcement. Our proposal emphasized these four imperatives to:

- Conduct leading edge aerospace $\&$ atmospheric science research and develop revolutionary new technologies by creating innovative, collaborative, synergistic partnerships among NASA's Langley Research Center, academia, and industry,

- Provide comprehensive graduate and continuing education in science and engineering by using both a local campus and exploiting innovative distance-learning concepts,

- Incubate and stimulate the commercialization of new intellectual property developed through the Institute's activities, including radical ideas and disruptive technologies, and

- Promote aerospace science and engineering and provide outreach to the region and nation.
\end{abstract}

As part of the fourth imperative, we specifically proposed to develop and conduct summer workshops for grade 6-12 teachers.

The goal of our workshops was to provide brief yet thoughtful introduction to some of the important scientific and engineering challenges involved in NASA's complex missions. One of these challenges included the development of lightweight, high strength composite materials. This paper describes the experiences teachers gained in the area of advanced composite materials as part of the 2003, 2004, and 2005 workshops.

Participation in the workshops, limited by space, schedule, and cost considerations, was limited to 26, including 2 supervisors, in 2003; 20 in 2004; and 19 in 2005. In all three workshops, teachers used the Vacuum Assisted Resin Transfer Molding process (VARTM) to fabricate woven polymeric composite panels. A mold was loaded with the preform made of reinforcement material. The mold was then closed and resin was introduced and flowed along the transverse direction of the preform.

Once cured, the teachers were able to cut tensile coupons and to evaluate the quality and consistency of the samples of the VARTM manufactured panels. The teachers actually produced four large panels. Twenty tensile coupons were cut from each panel and coupon tests enabled teachers to compare spatial variation of properties within a given panel produced during by the manufacturing process. In addition to the experience in processing, tensile testing and statistical analysis, the teachers became aware of cost considerations in manufacturing, since they were required to track materials and labor costs during the experimentation. 


\section{Introduction}

This workshop presents a low cost fabrication process known as Vacuum Assisted resin Transfer Molding (VARTM) used to manufacture composite laminates. It emphasizes mechanical engineering concepts such as ability to apply knowledge of science; ability to design a process to meet desired needs; knowledge of contemporary issues and the ability to solve engineering problems. The workshop is divided into three sessions. Each session runs approximately one hour and fifty minutes.

\section{Session One Overview of Composites}

This session introduces the teachers to composite materials and the different manufacturing techniques; however, the VARTM process is discussed in further detail. Teachers learn that a composite material is made of two or more chemically different materials with a distinct interface between them. The individual constituents maintain their own properties. However, the combination of materials develops a material that has properties and characteristics different than those of the original constituents. The properties of the composite material depend on the properties and geometry of the constituent materials and the distribution of the phases. They also learn about high specific strength and high specific modulus, improved corrosion and wear resistance, low thermal conductivity, and increased fatigue life typical of composites. . They also learn some specific disadvantages including cost, a lack of high productivity manufacturing methods, and clear-cut design rules. Some work is also devoted to the different fibers used such as glass, carbon, aramid, boron and alumina. They are also introduced to the more inexpensive and popular resins such as polyester, vinyl ester, cyanate ester and epoxy ${ }^{1}$.

\section{Methods Used in Manufacturing of Composites}

There are various methods that are used to manufacture composite laminates ${ }^{2}$. These methods include wet lay-up, prepreg method, autoclave processing, filament winding, pultrusion, resin transfer molding (RTM) and vacuum assisted resin transfer molding (VARTM). A brief description of these methods is given in the following section. This section also presents advantages and disadvantages of these various methods.

Wet lay-up is one of the oldest methods involving the laying of dry reinforcement (most often a fabric or a mat) into the mold and applying the resin. The wet composite is rolled by hand to evenly distribute the resin and thereby removing the air pockets. Another layer of reinforcement is laid on top, after which more catalyzed resin is poured, brushed, or sprayed over the reinforcement. This sequence is repeated until the desired thickness is reached. The layered structure is then allowed to harden (cure). This method is conceptually simple, does not require special handling of wet fabrics, and allows the resin to be applied only in the mold, thus helping to maintain a neat surrounding area. But it is very difficult to maintain product uniformity. Voids are common problem. Mechanical properties are low compared to other composite manufacturing methods. 
The Prepreg method is an extension of the wet lay-up method. The fabrics are usually a unidirectional tape or a woven fabric, impregnated with initiated resin, partially cured and then rolled up for shipment. But the prepreg method requires a vacuum bagging and is often autoclaved. The resin distribution in the prepreg method is usually very even and is controlled during tape manufacture. But this method is slow and labor intensive compared to the automated methods and has a potential high rejection rate because of faulty bagging procedures.

Autoclave processing consists of a vessel that can be pressurized internally up to 5 bar ( $\sim 75$ psi) and then the contents are heated. The vessel must be sufficiently large to accommodate large components. They are pressurized with gas, usually nitrogen that is circulated through the heaters to maintain a uniform temperature throughout the vessel. The basic feedstock for the process is preimpregnated warp sheets or prepreg. A raw laminate along with a bleeder pack is placed under a nonstick gas permeable film and then that is followed by a breather pack. This whole unit is kept in a vacuum bag to maintain vacuum pressure on the laminate. The outer membrane is pressed against the laminate by atmospheric pressure. The whole unit is then placed in the autoclave where the bagged molding may be reconnected with the evacuation system to maintain the vacuum. The autoclave is pressurized which augments the consolidated pressure. The temperature of the autoclave is reduced when the resin is adequately cured. The main aim of this process is to manufacture the laminate with uniform thickness and to ensure minimum porosity. The major difficulty in the autoclave process is the high capitalization cost and the stringent pressure code regulations.

Filament winding uses a continuous tape of fibers impregnated with resin which is wrapped over a mandrel to form a part. Successive layers are added at the same or different winding angles until the required thickness is attained. The mandrel or the application head can rotate to give the fiber coverage over the mandrel. Cylindrical parts can be manufactured with filament winding procedure. The pressure vessels, fuel and water tanks for storage and transportation and pipes can be manufactured by this method. Use of pressure during the cure is another method of making non-cylindrical parts. The process can be used to make parts with strength in several directions. This process can easily manufacture parts with high-pressure ratings. The difficulty of this process is programming the winding machine.

Pultrusion is performed by continuous reinforcement fibers being impregnated with resin and passed through a die. The part is then cured and available for use. As this is a continuous process, the production rate is very high. The cross section of the part has to be constant for using this process. But the thickness of the part produced can be varied by having a movable dies. The part usually gels in the die itself and is then fully cured when the part travels through a curing oven. The main advantage of this process is the high usage of fabrication material. But the problem can come when the resin or fibers accumulate and build up at the die opening and the equipment can jam. Voids can also result if the dies are run with too much opening for the fiber volume.

Resin transfer molding (RTM) is a process where a mold is loaded with the reinforcement material and then it is closed. The resin is injected into it. The mold with the preform is often put under vacuum so that the vacuum removes all the entrapped air in the preform and speeds up the RTM process. Typically, the resin is injected at the center of the top surface of the mold and the 
flow of resin occurs radially outwards till it reaches the vent lines. In this process the flow of the resin occurs in the plane as well as in the transverse direction of the preform. The fiber architecture, permeability of the preform and the fabric crimps has an influence on the wetting of the fabric.

Vacuum Assisted Resin Transfer Molding (VARTM) is a single sided tooling process where the dry preform is placed into the tool and vacuum bagged in conjunction with resin distribution and vacuum distribution lines. A low viscosity resin is drawn into the preform through the aid of vacuum. In the VARTM process, the flow of resin occurs in plane as well as in the transverse directions to the preform. The permeability of the preform, fiber architecture and fabric crimp has an influence on the wetting of the fabric. This process has certain advantages as listed below.

- $\quad$ Relatively low cost for high volume production

- $\quad$ Simple low cost tooling

- $\quad$ Very large and complex parts are practical

- $\quad$ High fiber volume fraction than hand lay-up

- $\quad$ On site manufacturing and repairing is possible

- $\quad$ Reduced environmental concerns than hand lay-up as it is closed system

This process is currently being used in many of the applications in the general aviation industry, the defense sector and in the transportation industry. The schematic for the fabrication is shown in the Figure 1 and is discussed in detail in the following section.

\section{Session Two Composite Manufacturing by Vacuum Assisted Resin Transfer Molding}

This section familiarizes the teachers with the various material characteristics and cost of the materials that will be used in the manufacture of the composite laminates.

\section{Material system}

In the present study plain-woven carbon fabric in conjunction with the epoxy vinyl ester is used to fabricate the composite panels. This plain-woven fabric $(3 \mathrm{~K}-70-\mathrm{P})$ is supplied by BGF Industries, Inc. ${ }^{3}$. The carbon fiber used in the fabric is $\mathrm{AS} 4^{\mathrm{TM}}$ manufactured by Hexcel Corporation ${ }^{4}$. The resin used is Derakane ${ }^{\mathrm{TM}}$ Momentum $^{\mathrm{TM}}$ 411-350 epoxy vinyl ester supplied by The Dow Chemical Company, Inc. ${ }^{5}$. The viscosity of the resin is $350 \mathrm{cps}$ at $77^{\circ} \mathrm{F}$ temperature. This is suitable to do VARTM at room temperature.

Once familiar with the materials, the teachers are trained in the processing used to manufacture VARTM composites; the steps for each process are listed below ${ }^{6}$ :

1. Mold preparation and fabric lay up.

2. Sealing off of the mold and applying vacuum.

3. Resin preparation and degassing.

4. Resin impregnation.

5. Post cure of fabricated panels. 


\section{Mold Preparation and Fabric Lay Up.}

In VARTM manufacturing several elements control the quality of the composite. The first element is the surface that the composite is made on, termed the mold. The acronym VARTM has the word mold in it (Vacuum Assisted Resin Transfer Molding). Since the mold is one of the major elements this is one of the most important. The mold was made from LEXAN ${ }^{\mathrm{TM}}$. LEXAN $^{\mathrm{TM}}$ is a transparent polycarbonate material that allows the flow of the resin to be observed and tracked during processing, if desired. Since LEXAN ${ }^{\mathrm{TM}}$ is a homogenous material, temperature variation problems were eliminated. LEXAN ${ }^{\mathrm{TM}}$ is also very resistant to scratching and chipping, and provides a consistently smooth surface without undulations for panel development. The mold measured 26 inches wide by 26 inches long by 1 -inch thick $(660 \mathrm{~mm} \mathrm{x}$ $660 \mathrm{~mm} \times 25.4 \mathrm{~mm})$.

The next two factors that provide for a higher quality composite are the manufacturing and the processing procedures used to make the composite. The following steps explain the VARTM manufacturing processes and provide detailed instructions of the manufacturing of the composite panels:

1. To ensure the cleanliness of the mold surface, wax was applied to the surface of the LEXAN $^{\mathrm{TM}}$ mold. The wax was allowed to dry and a clean towel was used to remove the wax and then polish the surface. This was performed a minimum of three times. On the third and final time, the wax was left on the mold surface. This aided in the removal of the Mylar ${ }^{\mathrm{TM}}$ sheets and the cleaning of the mold for the next time.

2. The second step involved a sequence of events. First, the mold was covered with a two-mil polyester film (Mylar ${ }^{\mathrm{TM}}$ ) that acts as a mold protection. The Mylar ${ }^{\mathrm{TM}}$ sheet was approximately two mil (254 micron) thick and provided a smooth surface for the composite panel to form against. It helped facilitate easy removal of the panel from the mold surface after green cure. The Blue sealant tape has a special adhesive that does not react with the resin or the curing agent during impregnation of the fabric, but it does provide good adhesion and sealing of any material that it is used upon. The bottom peel ply was a porous nylon fabric that transferred its rough fabric imprint onto the final panel. The rough imprint provided a rough surface that could be easily bonded to and tabbed when the panel was cut into smaller specimens for testing. As stated earlier, the fabric was woven carbon. The fabric was cut into panels by measuring out a square 14-inch by 14-inch (356 mm x $356 \mathrm{~mm}$ ) and applying a one-half inch $(12.7 \mathrm{~mm})$ wide strip of masking tape along the entire length of the fabric. A razor cutter was used to cut down the center of the tape providing a one-quarter inch $(6.35 \mathrm{~mm})$ border. Ten panels of this size were cut and delicately handled so as not to misalign the warp and weft (90-degree) alignment. The top peel ply was the same material as the bottom peel ply. Figures 1 through 5 illustrate the different layers that were applied in Step 2. 


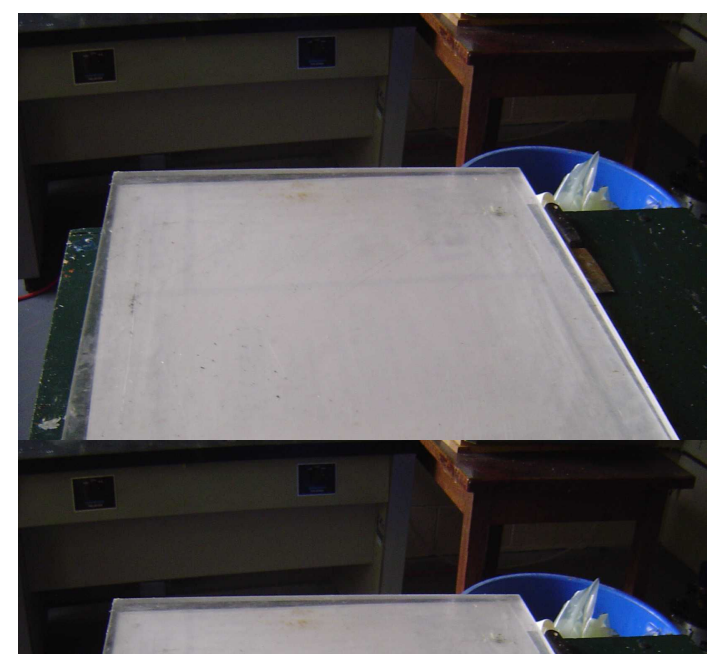

Figure 1. Clean waxed LEXANTM Mold

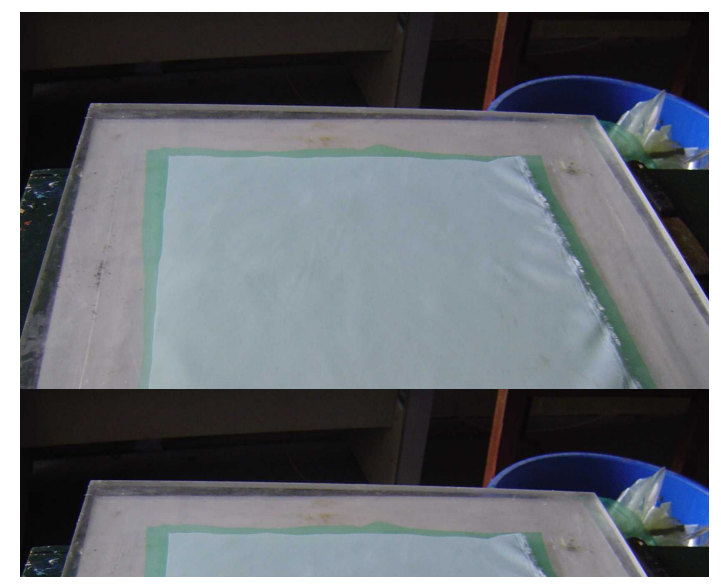

Figure 3. Bottom peel ply on mold.

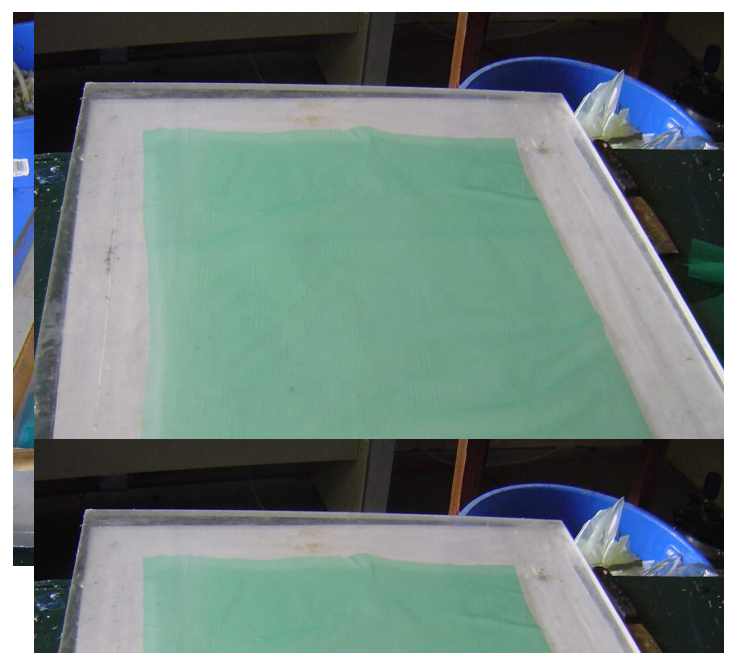

Figure 2. MYLARTM laid onto Mold

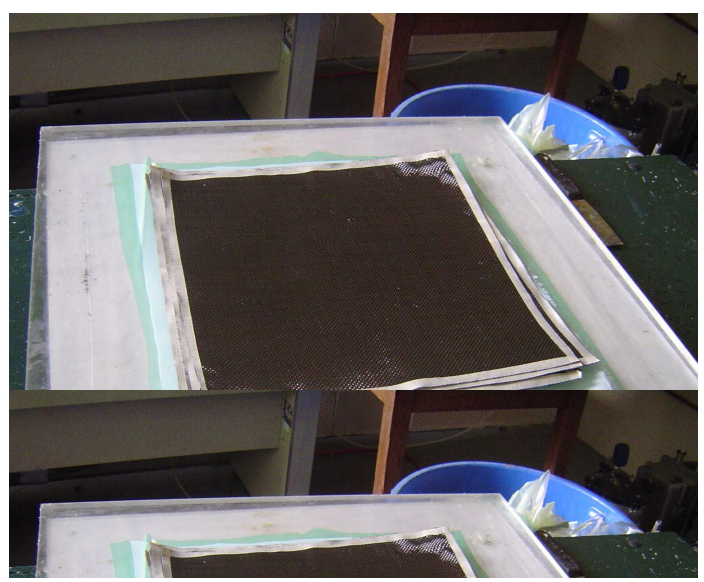

Figure 4. Ten layers of woven fabric.
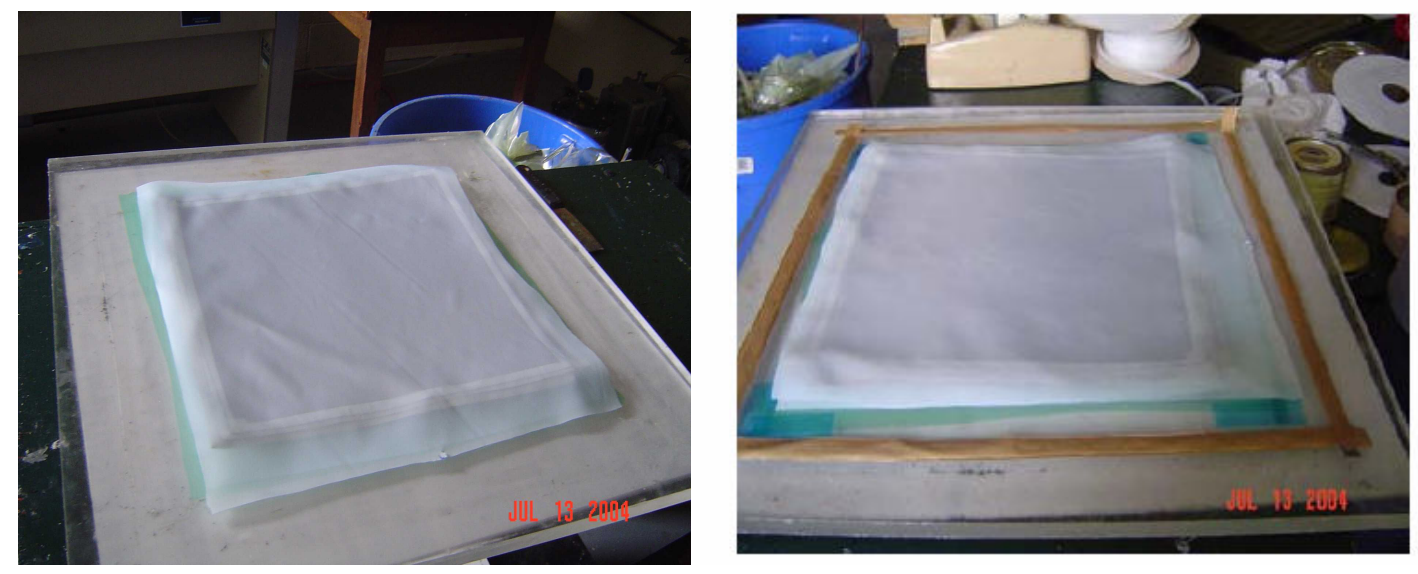

Figure 5. Top peel ply on fabric. Figure 6. Sealant tape applied around materials. 


\section{Sealing Off Of the Mold and Applying Vacuum.}

3. In the third step, a sealant tape was applied around the mold. Mastic was extended approximately two inches past the fabric and peel ply materials on the mold. When the corners of the mastic were overlapped, the paper on the mastic was peeled back at the corners exposing the sticky mastic, approximately one inch past the overlap of the mastic. The paper on the mastic was removed entirely at a later time. The paper allowed work to continue without anything sticking to the mastic until the appropriate time. The mastic material was placed as stated above or at a location where it actually was laid on the LEXANTM mold and not on the MYLAR $^{\mathrm{TM}}$. This ensured a good vacuum whereas if the material was laid on the Mylar ${ }^{\mathrm{TM}}$, it would produce a vacuum leak. The mastic was worked on several times to ensure a good seal. First, pressure was applied by running a finger over the paper of the mastic from one end to the other. The pressure causes the adhesive of the mastic to seal against the clean LEXANTM. Next, the corners of the mastic were worked upon to ensure a good vacuum. Earlier, the paper on the corner mastic was removed and the two layers were pressed together. Here, pressure was applied again to the overlap of the mastic, which removed any air pockets between the mastic and the mold. Again, finger pressure was applied from the corner and around the mold until all of the entire mastic tape was pressed down. Figure 6 illustrates the mold after application of the sealant tape.

4. The fourth step was crucial. It involved the placement of the vacuum and resin distribution lines. Special purpose tubing termed spiral cut HDPE (High Density Polyethylene) tubing was used for both the vacuum and the resin distribution lines. The spiral cut tube was cut approximately twenty inches long $(508 \mathrm{~mm})$. One end of the tubing was taped shut and approximately five inches $(127 \mathrm{~mm})$ of the other end was pushed into a 48 -inch $(1219.2 \mathrm{~mm})$ long section of 5/16 inch $(7.9 \mathrm{~mm})$ outer diameter $1 / 4$ inch $(6.4 \mathrm{~mm})$ inside diameter polyethylene vacuum tubing. Sealant tape was wrapped around the connection to keep the spiral tubing from being pulled out. One side of the fabric was chosen to apply resin and place the vacuum line; the resin distribution line was to be placed on the other side. On the vacuum side; the end of the spiral tubing that was taped shut was laid one inch $(25.4 \mathrm{~mm})$ past the fabric and securely taped to the MYLAR ${ }^{\mathrm{TM}}$. The spiral tubing was then pulled parallel along the fabric, just touching the edge of the fabric. The point at which the spiral tubing entered the polyethylene tubing was pulled until it was at least one inch past the fabric on the opposite side. The entire length of the spiral tubing had to be in contact with the fabric. On the opposite side of the fabric, the same process was followed for the resin distribution line. The two lines were laid in opposite directions (Figure 7). The vacuum tubing connected to the spiral lines was attached on opposite corners. This was done so that a vacuum path would pull and distribute resin over the entire panel diagonally.

The resin input line was laid approximately two to two and one-half inches $(50.8 \mathrm{~mm}$ to $12.7 \mathrm{~mm})$ away from and parallel to the fabric so that it would not touch the fabric on this side. The polyethylene vacuum tubing was pulled across the mastic on both the vacuum and resin input line corners. Mastic was cut into an approximate five-inch $(127 \mathrm{~mm})$ length and wrapped around the vacuum tube. 


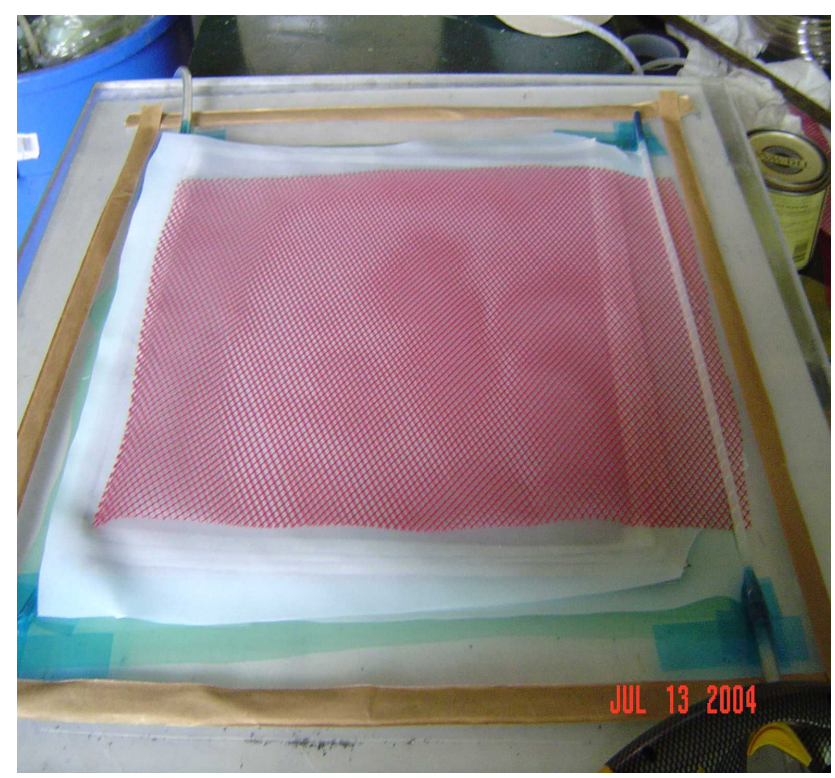

Figure 7. Resin distribution media.

similar to a bow tie. It was applied at a distance on the tube so that when pressed down it would stick to the previously laid mastic. Once the mastic was wrapped around the tubing, the paper on the mastic on the mold was removed. The bow tie mastic and the mold mastic were pressed together and worked onto the mold. This process was followed for both the vacuum and the resin lines. On the vacuum side, the spiral tubing was placed between the top and bottom peel plies, just touching the fabric. On the resin distribution side, the spiral tubing was placed on top of both of the peel plies.

5. Another piece of material, termed resin distribution media was cut into a thirteen inch by seventeen inch $(330 \mathrm{~mm} \times 432 \mathrm{~mm})$ piece. It was slid under the resin input line spiral tubing and adjusted until it was approximately one inch away from the vacuum spiral tubing. It was also adjusted from side to side leaving one-half inch on either side of the AS4 fabric below, on top of the top peel ply. The resin distribution media is a polyethylene mesh laid on top of the peel ply to maintain an even distribution of resin and facilitate the flow of resin through the thickness of the panel. As resin travels through the mesh, it fills the pockets in the mesh. The filling of the pockets controls the flow. Once resin has filled the mesh, the resin then flows through the thickness of the fabric. This mesh material is a patented technology known as SCRIMP (Seemann Composite Resin Infusion Manufacturing Process) invented by Bill Seemann [1994].

6. The sixth step covered the placement and sealing of the vacuum bag. A vacuum bag was cut to fit over the mastic, allowing approximately 2 inches of overlap adjustment; thus the bag material was approximately 20 inches by 20 inches $(508 \mathrm{~mm}$ x $508 \mathrm{~mm})$. This bag was placed over the mastic and aligned to leave the stated overhang on each side. The paper on the mastic was removed on one side of the mold. Finger pressure was applied on the top side of the bag against the mastic. The bag was adjusted by pulling to the opposite side, to remove any wrinkles. The bag was pulled tightly across to the opposite side and the paper on this side's mastic tape was removed. While the bag was being pulled tight, finger pressure was applied over the bag and mastic, again removing any wrinkles. The same process was followed for the other two sides, with two exceptions, the sections that had the resin and the section that had the 
vacuum lines. Special care was taken around these sections of the bag. One of the two lines was chosen and finger pressure was applied on the top.

The vacuum tubing line was attached to a vacuum pump via a paint collection tank. The vacuum pump was turned on and the vacuum was applied. The paint collection tank was used to catch any excess resin from the impregnation process. As the vacuum was applied, air was pulled from the bag and the bag was pulled down, applying pressure to the fabric. The resin input line was left open during this time. After the wrinkles in the bag were smoothed out on the bag and the panel, the resin vacuum line was clamped off approximately 2 inches $(50.8 \mathrm{~mm})$ from its end. The panel was again checked for air leaks. Usually, the air being drawn in produces hissing sounds and is easily found. The most frequent leaks are around the resin input and vacuum lines. Usually, application of pressure onto these areas will close off any leaks. It is also a good practice to apply finger pressure over the entire length of mastic again. Several methods can be used to detect leaks. One such method is Ultrasonic detection. A more scientific method is to use a vacuum gauge to check for vacuum loss. In this process, the resin line has an electronic vacuum gauge placed into it. After a period of time, usually overnight, but typically after approximately 2 hours of vacuum application, the vacuum line is clamped off and the vacuum pump is turned off. An initial reading of the vacuum pressure on the gauge was measured. At the vacuum gauge, a reading was recorded again.

7. If the bag or vacuum pressure did not lose more than 20 percent of the original vacuum reading, the vacuum was considered good. The vacuum pressure of the bag was dependent on several factors. The bagging material could expand and stretch as much as 300 percent, thus the bag could expand and the pressure could drop. The temperature and the relative humidity could also affect the vacuum, causing the bag to drop pressure. Small pinholes can also occur due to the creasing of the bag during installation. Many things can affect the vacuum pressure, thus it is critical to be diligent during the set-up and bagging steps. An electronic vacuum gauge is illustrated in Figure 8; it illustrates a good vacuum of 1.5 torr. After following this bagging process many times, discussing how vacuum pressure on the fabric related to the improved fiber volume fraction with other researchers and reading several articles on this subject, for example Mouritz et al. [1997], an additional step was added to the process. This step involved the application of another layer of bagging material over the top of the previous setup; this process is termed double bagging. The benefits of this step are that if the inner bag pressure drops, the outer bag provides a second vacuum to maintain pressure. The second bag also provides additional pressure on the fabric and resin materials. This additional pressure produces a more consistent panel thickness in both directions. The pressure compresses the fibers and helps produce a higher fiber volume fraction and thickness that is more consistent across the final panel, which was illustrated in the data from the fiber volume testing and the thickness measurements.

8. In the double bagging step, another layer of mastic was laid around the previous

bagged materials. It was located approximately $2-3$ inches $(50.8 \mathrm{~mm}-76.2 \mathrm{~mm})$ away in the same fashion as in Step 3. The corners of this mastic were worked by the same method. 


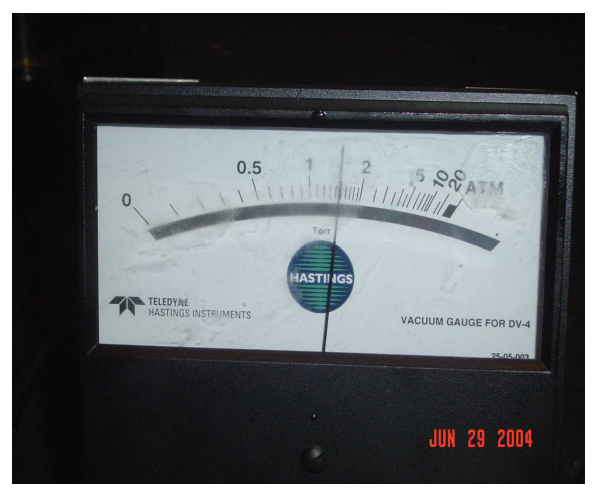

Figure 8. Electronic vacuum gauge.

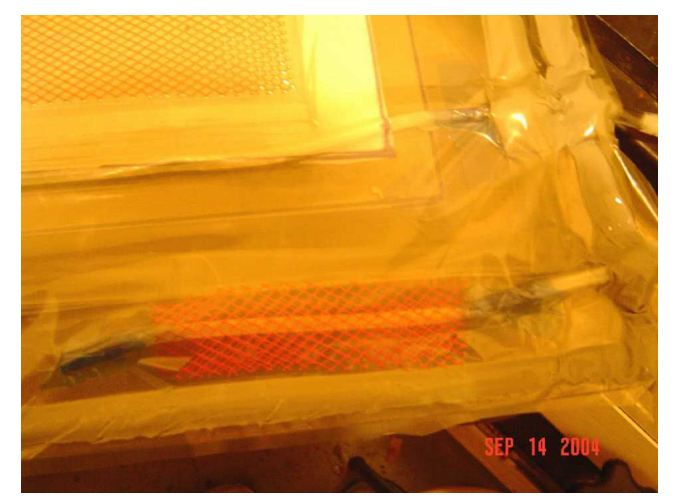

Figure 9. Distribution media.

A 2- foot $(609.6 \mathrm{~mm})$ length of polyethylene vacuum tubing was cut and approximately 10 inches $(254 \mathrm{~mm})$ of spiral tubing was cut and pushed into the vacuum line. The end of the spiral tubing was taped. This combination was taped down between the first bag and the new mastic. The vacuum tubing had mastic wrapped around it, similar to Step 4. The vacuum tubing and mastic were pressed onto the new outer mastic. A one-inch $(25.4 \mathrm{~mm})$ by eight-inch $(203.2 \mathrm{~mm})$ piece of distribution media was cut, placed and tapped on top of the spiral tubing, as shown in Figure 2.23. A 27 -inch by 27 -inch $(685.4 \mathrm{~mm} \times 685.4 \mathrm{~mm})$ piece of bagging material was cut and placed over the mastic. The paper on the mastic was removed and the bag was worked in the same fashion as in Steps 6 and 7. Once all the wrinkles were removed, this vacuum tube was connected via a $\mathrm{Y}$ connector to the previous vacuum tube that was connected to the vacuum pump. The pump was turned on and the air was removed from this outer bag. A check for air leaks was conducted. The same process of rubbing the mastic lines with finger pressure was performed. This process was conducted until a good vacuum was obtained and all wrinkles were removed. The vacuum tube of the outer bag was clamped shut and a check of the bag was done. If the vacuum was good, the next step was conducted, if not, the setup was reworked until a good vacuum was achieved.

\section{Resin Preparation and Degassing}

9. In order to determine how much resin and curing agent was necessary for mixture, the following process was performed. The panel size and an individual thickness of one ply of fabric were measured. The following calculations were then performed. Since there were ten plies used in this work, the thickness was ten times the individual thickness.

Width $\mathrm{x}$ Length $\mathrm{x}$ Thickness $\mathrm{x}$ \# of Plies

14.0 inch x 14.0 inch $\times 0.01$ inch $\times 10=19.6$ in $^{3}$

This volume value was converted into cubic centimeters $\left(\mathrm{cc} \mathrm{or} \mathrm{cm}^{3}\right)$ by the following calculation: 19.6 in $^{3} \times 2.54 \frac{c c}{i n^{3}}=321 \mathrm{cc}$ 's.

In order to obtain the correct ratio of fiber to matrix, (e.g., if 50\% was desired), the volume was converted to mass. Using the formula: Density = Mass/Volume and rearranging to obtain mass, the equation becomes Mass $=$ Volume * Density. The density of EPON ${ }^{*} 9504 \AA$ resin is 


$$
1.13 \frac{\mathrm{grams}}{\mathrm{cm}^{3}}
$$

Using the above equation, $321 \mathrm{~cm}^{3} \times 1.13 \frac{\text { grams }}{\mathrm{cm}^{3}}=362.34$ grams of mass.

Typically, ten percent extra is usually added to make up for the resin used to fill the resin input line and the mesh pockets of the resin distribution media before infusion into the fabric. This amount was approximately $1.3 \mathrm{oz}$ (37 grams). The two amounts of mass were combined and gave approximately $14.1 \mathrm{oz}$ (400 grams) resin. Using the ratio of resin to curing agent (100:26) from the specification sheet, an amount of approximately $14.1 \mathrm{oz}$ (400 grams) of EPON® 9504 required $4.1 \mathrm{oz}$ (117 grams) of the EPI-CURE ${ }^{\mathrm{TM}} 9554$ Curing Agent.

10. A clean measuring bucket was set onto the OHAUS Explorer Pro Digital scale and a tare reading was completed. To tare is to zero out any weight on the scale.] The EPON 9504 resin was carefully poured into the mixing bucket until $14.1 \mathrm{oz}$. (400 grams) was obtained. The bucket and resin were removed and set aside. Another measuring bucket was placed onto the scale and torn. The $4.1 \mathrm{oz}$. (117 grams) of EPI-CURE ${ }^{\text {TM }} 9554$ Curing Agent was measured into this bucket. A wooden stirring paddle was placed into the EPON resin and stirred around. This process coated the paddle to keep the wooden paddle from absorbing any of the curing agent, which would change the mix ratio. The curing agent was slowly poured in with the resin. The mixture was stirred as the curing agent was poured in. Stirring was done for approximately five minutes. The bucket with the resin and curing agent combination was placed into a degassing chamber to remove any air bubbles produced by stirring, while in the degassing chamber, the mixture was placed under vacuum. The vacuum was cracked open every two minutes to remove the foam formed by removal of the air bubbles. If the chamber was not cracked, the mixture would foam, exotherm and harden. This degassing process was conducted for approximately 12 minutes.

\section{Resin Impregnation.}

An adjustable hose clamp was placed on the resin input line one inch away from the previously placed clamp. The vacuum tubing was then slid onto the $1 / 4-\mathrm{NPT}$ hose barb that was already screwed into the bottom of the resin flask. The vacuum pump was turned off and the lid was removed from the degassing chamber and the mixture was then gently poured into the resin flask, see Figure 10. The VARTM process was now ready to be performed.

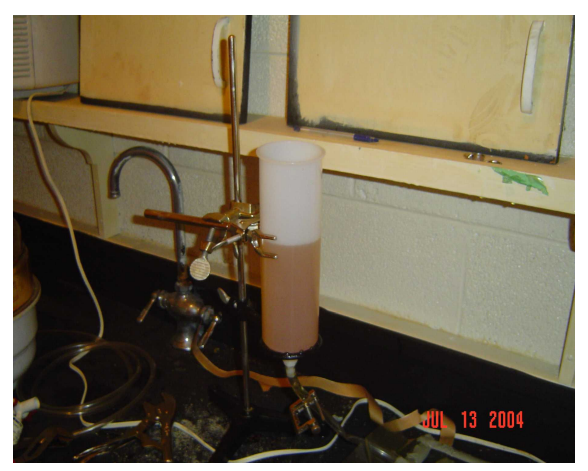

Figure 10. Resin flask with hose clamp. 
After making several panels with the VARTM process, it was concluded that the rate at which the fabric needed to be infused should be controlled and set to a certain rate. Flow rate can be calculated by several methods. In this case, the rate refers to the distance the resin travels from the starting point to one inch across the panel. The dark patch across the panel in Figure 11 illustrates the resin moving in the fabric. Once the resin has stabilized and can be measured, a mark was drawn across the panel at the resin and the distance traveled in one minute was measured. Several different rates were tried before the best rate was found: four inches per minute, 2 inches/minute $(50.8 \mathrm{~mm} /$ minute $), 1-1 / 2$ inches/minute $(38.1 \mathrm{~mm} /$ minute $)$ and 1.0

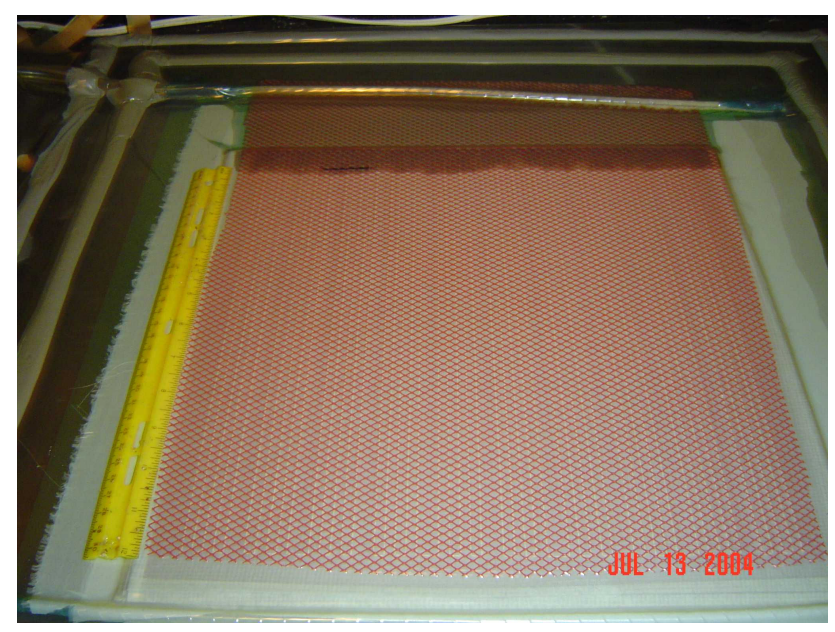

Figure 11. Calculation of resin flow rate.

inches/minute $(25.4 \mathrm{~mm} /$ minute $)$ and so forth. The last two rates were too fast and too slow, respectively, so a rate of 1.25 inches /minute $(31.8 \mathrm{~mm} /$ minute $)$ was selected.

As the resin traveled across the top of the fabric, the resin at the bottom of the panel lagged behind. This lag produced an interesting aspect to the flow. If the resin traveled too fast, air was trapped on the bottom of the panel in small pockets below the fabric. During the VARTM process, or after infiltration of the fabric, the air did not have the ability to escape. These air pockets produced small voids in the final composite panel as they traveled in the fabric trying to escape. As the speed of the resin slowed, the lag between the top and bottom was reduced. This reduction in the flow rate of the resin eliminated the vast majority of the air pockets and voids in the final composite panel.

11. Infiltration of the panel began at this step. The clamps were removed and just as the resin was observed entering the fabric, a mark was drawn on the bag and a stopwatch was started. At the end of one minute, the distance the resin had traveled was measured using a ruler, as illustrated in Figure 11. An adjustable hose clamp was used to control the flow rate of the resin. It could be adjusted by the turn of the screw, which restricted the flow of resin through the resin line. A flow rate of 1.25 to 2.00 inches $(31.8$ to $50.8 \mathrm{~mm})$ per minute provided good results. In previous research, the flow rate was not measured since the resin and catalyst were freely flowed. Once the flow rate of the resin was adjusted, the resin was allowed to flow through the fabric. The flow rate was checked several times during the infiltration to ensure that the resin was still flowing correctly. If not, the adjustable hose clamp was adjusted to give the correct flow rate. Flow of the panel was usually completed in approximately 13 to 18 minutes. The 
times from mixing, stirring, degassing and flowing of the panel provided an approximate total time between 35 to 50 minutes. This was well within the gel time found for the $80{ }^{\circ} \mathrm{F}\left(26.6{ }^{\circ} \mathrm{C}\right)$ temperature. The infiltration process of the panel was completed. The infiltration process used the vacuum in the bag to draw resin into the vacuum to fill the void of the vacuum. The fabric was in the void and therefore was filled with resin. The use of a pump was not needed. Once the panel was flowed and the excess resin entered the vacuum line, the resident trapped air bubbles in the resin needed a place to escape. At this point, the vacuum pump was turned back on. When the vacuum pressure of the paint tank reached the same level as the bag, the clamp on the vacuum line was removed. The pump then pulled these air bubbles into the paint holding tank. The vacuum was adjusted to maintain a positive flow. The vacuum was applied to pull the resin and air bubbles out until the resin gelled and began to harden, thus removing any excess air bubbles. As the resin gelled, it began to exotherm and cure, which ensured that none of the resin would be removed from the panel. An illustration of this process is provided in Figure 12. The panel remained untouched for 16 hours. During this time the material was green curing.

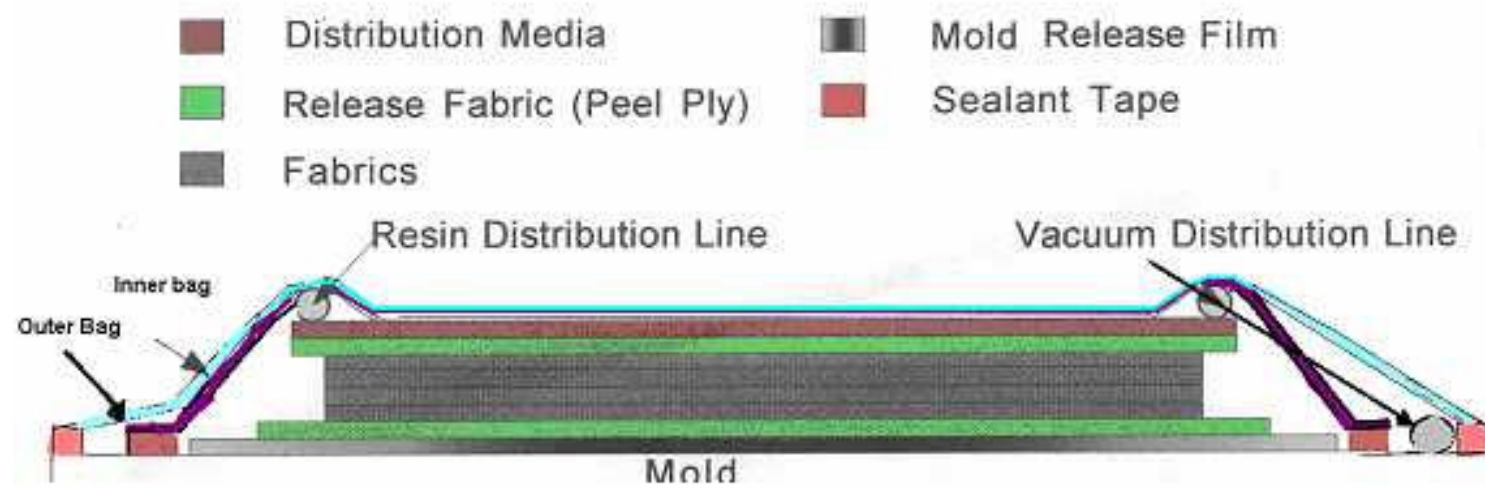

Figure 12. Side view of the different materials used in the VARTM process.

The new composite material was fragile at this point and was handled gently. After 16 hours, the vacuum bags were opened and the composite panel was gently removed. The peel plies were peeled away and the tubing was removed. The green panel was taken to be post cured.

\section{Session Three Curing and Testing of Composite Laminates}

\section{Post Cure of Fabricated Panels}

In order to finish curing the composite, the green panels were hung in a Blue M Oven Model $\mathrm{MP}-1406 \mathrm{~F}$. The manufacturer suggested a set cure rate at set temperatures. Post cure was the final and one of the most important steps in the VARTM process. The cure can be done at room temperature but requires extremely long periods of time. The post curing at elevated temperatures accelerates the curing process. The post cure also determines if the final mechanical properties are achieved. The following process was followed on the green panels. The panels were hung in the oven as stated above. The controller was programmed to ramp from room temperature $70{ }^{\circ} \mathrm{F}\left(21.1^{\circ} \mathrm{C}\right)$ to $200{ }^{\circ} \mathrm{F}\left(93.3{ }^{\circ} \mathrm{C}\right)$ at one degree per minute. The controller held the temperature at $200{ }^{\circ} \mathrm{F}\left(93.3^{\circ} \mathrm{C}\right)$ for one hour. After one hour, the controller ramped 
down the temperature to room temperature $70^{\circ} \mathrm{F}\left(21.1^{\circ} \mathrm{C}\right)$ at one degree per minute and held it there for 2 hours, as demonstrated in Figure 13.

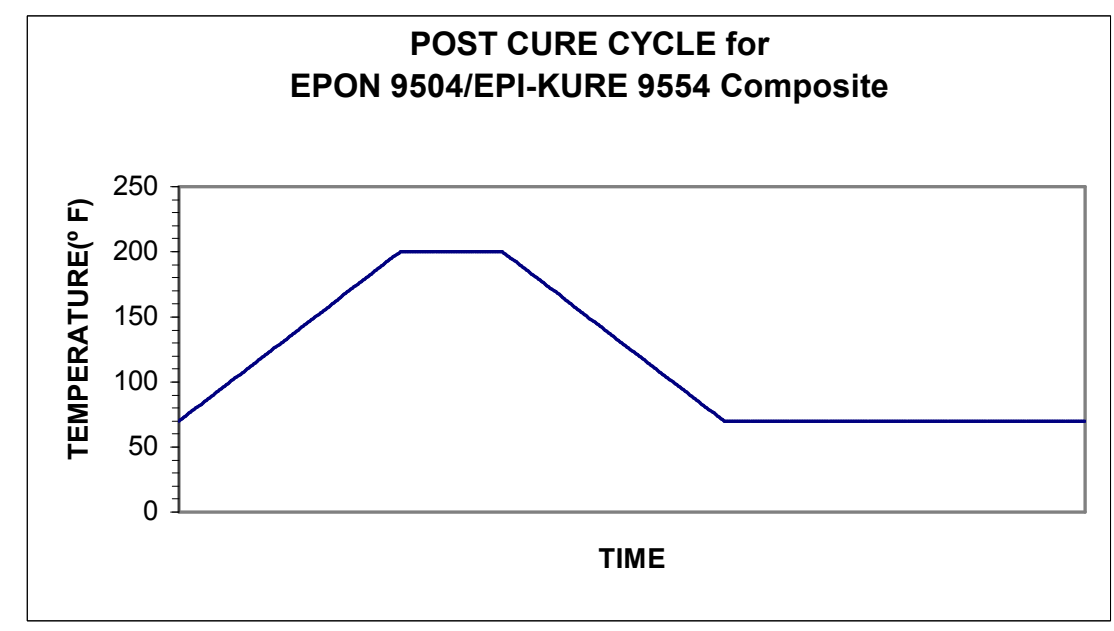

Figure 13. Post Cure cycle for Epon/AS4 composite laminates.

A total of 4 carbon/epoxy composite panels were manufactured. These panels were taken and cut into test coupons per ASTM 3039 standards for tensile testing. A photo of one of the final panels is shown in Figure 14 and a photo of a tabbed test coupon is given in Figure 15.

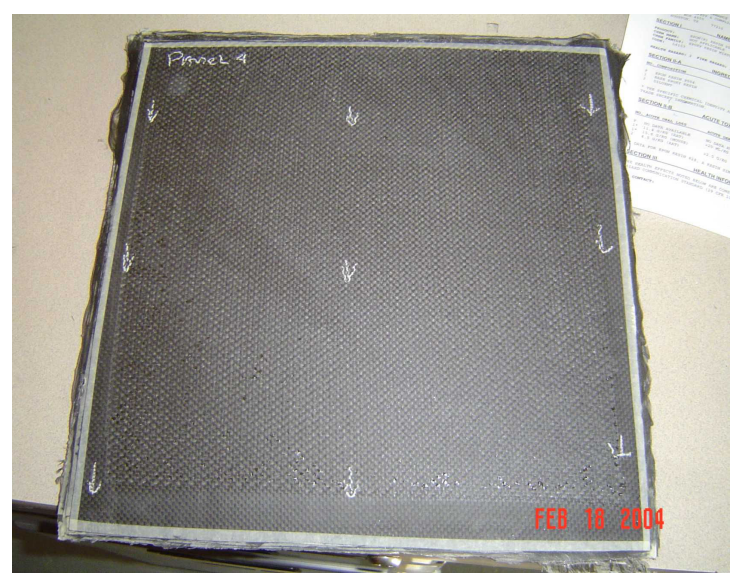

Figure 14. Post Cured VARTM Composite Laminate.

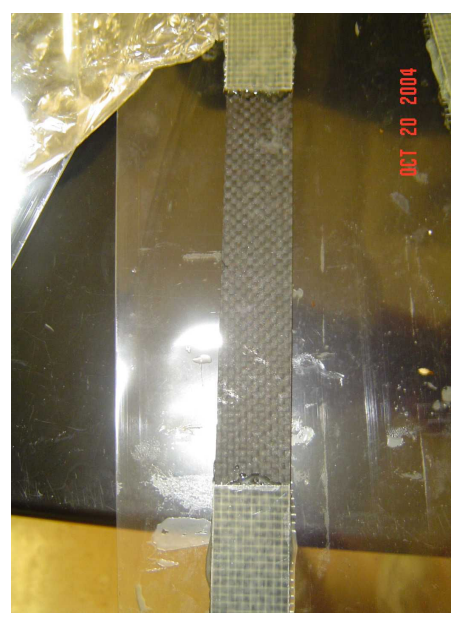

Figure 15. Test coupon from panel.

Once panel manufacture and the curing process has been completed, the teachers are informed to the material cost and are to determine how much the procedure and processing of a composite laminate costs. This section of the workshop provides teachers with an understanding of the manufacturing engineer and how the processing of the composite and the engineering of the composite all go together to make the best and most cost effective product possible. The data provided on the material cost is illustrated below: 


\section{Material Cost}

1. Glass fabric plain weave $\$ 300.00$ per roll (approximately $\$ 0.2$ per sq. ft.). Each roll is $300 \mathrm{ft}$. long and $5 \mathrm{ft}$. in width.

2. Vinyl ester resin 5 gallon for $\$ 50.00$ (approximately $\$ 2.3$ per $\mathrm{Kg}$.) 5 gallon $\sim 21.5 \mathrm{Kg}$

3. Other related fabrics for VARTM approximately $\$ 10.00$ per panel of size 2' $x 2$ '. Eight layers 2' x 2' glass composite panel consumes approximately $1 \mathrm{Kg}$ resin. Thus the total cost will be $\$ 6.4$ for glass fabric $+\$ 2.30$ for resin $+\$ 10.00$ for other fabrics $=\$ 18.70$ per panel.

\section{Assessment}

In each of the three workshops to date, there was a required assessment by participating teachers. As part of the general assessment process, teachers provided comments of workshop presentations by faculty and graduate students, facilities, meals, and other items. In every case, teachers were complimentary of the composites activities. In the information that follows, it is clear that the composites experience was a highlight of the program. Our participants generally felt that the lectures and the hands-on activities complemented each other well. Our teachers also seemed to appreciate demonstrated principles of strength and manufacturing processing rather than advanced concepts. All of this helped prepare our teachers for the tours and discussions during the following week at NASA's Langley Research Center.

Assessment forms were provided to participants for all summer workshops since inception, (2003-2005), however in our first summer, the assessment instrument was general and did not include an analysis of the best presentations. For the last two summer workshops, teachers were asked to evaluate each activity for quality, relevance, and importance to their teaching activities. For the 2004 summer workshop, Topics were divided two categories, I-Sessions Most Relevant to Students and II-Sessions most personally interesting to the teacher as a Scientist. Composite Materials ranked number 2 of twenty topics under session I and number 1 (highest rated topic) of 20 topics in session II. The other major high-level topics (most related to NASA missions) of the 20 included: Bottle Rockets, Controlling Spacecraft, Gas Turbine Engines, Life in Space, Lego League, and Mars Dessert Research Station, Mathematical Modeling of Planetary Orbits, Smart Materials and Tumbleweed (A Mars Roving Experiment).

For 2005, the assessment scheme was again revised and separated into two categories (Middle School teachers and High School teachers). For each group, participants were asked to provide assessments under three columns. Column 1 was aspects most enjoyed, Column 2 was Top Three favorite Activities/Lectures, and Column 3 was Most Intriguing Lecture/Activity to a Scientist. The middle school group of 10 people ranked composite materials in their top three favorite activities in 9 of 10 cases. By far, this was the most popular activity followed by Space Travel Biomechanics. The high school group of 8 ranked composite materials within the top three favorite activities in 6 of 8 cases; in addition, this group ranked it the first choice in ALL 6 cases. Clearly, composite materials continue to be a hot and interesting topic for our audiences year after year. 


\section{Conclusions}

At the end of three sessions, the following is expected to be obtained. The teachers go away with a better understanding of a new manufacturing process of an advanced material. Throughout the process the teachers are encouraged to keep a journal of each step of the workshop. They are told to write down their thoughts and problems in each step of the manufacturing process and provide insight to improve the workshop. They then develop a folder of the various materials and instructions to take back and share with their students, to continue the learning process. Phone numbers and email addresses are exchanged to continue discussion if needed at a later point in time.

\section{Acknowledgements}

The authors would like to acknowledge the assistance of Department of Mechanical Engineering at North Carolina A\&T State University involved in the organization of the program and in composites structures and demonstrations. In addition we wish to thank North Carolina Space Grant, the National Institute of Aerospace and NASA for supporting funds and facilities. Also support from

\section{Bibliography}

1. Daniel I. M.; Ishai Ori; 1994, "Engineering Mechanics of Composite Materials", Oxford University Press

2. Strong A. B.; 1989, "Fundamentals of Composite Manufacturing: Materials, Methods, and Applications", Society of Manufacturing Engineers

3. BGF Industries, Inc.; "http://www.bgf.com/cchart.htm

4. Hexcel Corporation, Inc.; "http://www.hexcelfibers.com/Markets/Products/Continuous /_Productlist.htm"

5. The Dow Chemical Company, Inc.; "http: /www.dow.com/ derakane specific/product/ 411-350.htm"

6. Kelkar Ajit D. and Tate Jitendra S.; 2002, "Low Cost Manufacturing of Textile Composites Using Vacuum Assisted Resin Transfer Molding”, All India Manufacturing Design and Research Conference, Ranchi, India, December 2002. 